\title{
Sound Absorbing Insulating Composites Based on Polyurethane Foam and Waste Materials
}

\begin{abstract}
ANCUTA ELENA TIUC ${ }^{1 *}$, OVIDIU VASILE², HORATIU VERMESAN ${ }^{2 *}$, PLATON MIHAI ANDREI ${ }^{1}$
${ }^{1}$ Technical University, Faculty of Materials and Environmental Engineering, Cluj-Napoca, 28 Memorandumului Str., 400114, ClujNapoca, Romania

2Politehnica University of Bucharest, Department of Mechanics, 313 Splaiul Independentei, 060042, Bucharest, Romania

The acoustic comfort includes the protection against noise and it is closely related to the sound absorption concept. This paper presents an experimental study on sound absorption coefficients, for some composite materials: waste materials (rubber crumbs, textile, flax fibers) mixed with rigid polyurethane foam as binder. The composite materials were characterized both acoustically (sound absorption coefficient) and also in terms of heat transfer (thermal conductivity). The acoustic absorption coefficient was determined using the impedance tube and the influence of structure of these materials on the sound absorbing properties was analyzed. The experimental results show the sound absorption performances of some composites based on recycled waste materials, thus promoting environmentally friendly solutions.
\end{abstract}

Key words: recycled rubber crumbs, textile waste, polyurethane foam, acoustic materials

Environmental noise is unpleasant and harmful, and sometimes has severely negative effects on communication, health and quality of life. Sound insulation, otherwise known as sound reduction, is the prevention of sound being transmitted from one building to another. Good sound insulation is a crucial part of living comfort; itenables proper conditions for sleep, rest and work in a residence withoutdisturbance from neighbors or other external noise.

The noise reduction mechanism of sound reflection in the case of sound insulating materials is different from that of sound energy loss caused by the interaction with fluid or solid as sound absorbing materials [1].

Currently, waste is one of the most serious environmental problems [2]. Industry however, is able to recover or remove waste. In literature there are several studies on recovering various types of waste by making composite materials with sound absorbing properties [3].

Use of fibers in composite materials products represents a high value application, in comparison to the common use. Research confirms the possibility to use different types of fibers, natural or synthetic, in making composite materials with acoustic properties. Thus, researchers have used different waste with fibrous characteristics to obtain sound absorbing materials: cellulose fibers $[4,5]$, cotton [6], bamboo fibers [7], hemp fibers [8], jute fibers [9], banana fibers, non-woven short polypropylene fibers [10], coconut fibers [11, 12], textile fibers [13], agricultural waste [14], tanned leather [15] and waste glass fibre [16, 17].

From the view point of environmental protection, natural bamboo fibers were used for sound absorbing purposes. Impedance tube measurement of the bamboo fibre samples, showed similar properties to that of glass wool [7]. Coconut coir fibre compressed into bales and mattress sheet was found to demonstrate a good sound absorption coefficient [11].

As a natural and environmentally friendly material, tealeaf-fibre has been tested for its sound absorption properties. Tea-leaf-fibre is a waste product of tea-leave processing, extracted after drying and chopping of the leaves [18].

Rigid polyurethane foams and their composites possess a wide range of performance properties such as low apparent density, good mechanical properties, low thermal conductivity and excellent damping abilities [19].
The use of recycled rubber in the production of sound absorbers can help to solve the existing problems of both waste disposal and noise pollution [20]. Zhou et al. [21] found that recycled rubber has some excellent sound energy absorption properties and the composite panel made with recycled rubber crumbs created some good noise attenuation.

Development of innovative low costinsulating materials complies with 2010/31/EU [22], which is a Directive that establishes that all new constructions have to be nearly zero energy waste buildings. In addition, low cost insulation materials can be exploited in case of renovation of existing buildings to reduce energy demand [23]. Thermal insulation in buildings contributes not only to reduce the size of the air-conditioning system, but also the annual energy consumptions [24].

This study investigates the possibility of using waste materials (recycled crumbs, flax fibres and textile waste) as composite materials with rigid polyurethane foam (RPF) as binder, and the potential applications of these materials. The used method for achieving the composites is an ecological recovery method, with low energy consumption and low costs. The novelty of this study consists in the use of insulating systems made of waste materials, which is a highly convenient solution due to these composites good acoustic and thermal properties.

\section{Experimental part \\ Materials}

The binder used in composite materials enables the bond with the reinforcing material and establishes the final structure of the material.

For the production of composite materials from textile wastes, rubber crumbs and flax fibres with sound absorbing properties, a system of bi-component polyurethane foam was used as binder, for obtaining a material with a rigid structure and closed pores.

The polyol component of the foam mixture contains polyol, catalyst and other additives (BASF, Elastopor H1221/ $41)$. The isocyanate component contains a diphenyl methane diisocyanate mixture (pMDI).

The crumbs of recycled rubber (fig. 1a)) have a size of 1 $\div 10 \mathrm{~mm}$ and a density of $0.3 \mathrm{~g} / \mathrm{cm}^{3}$. 


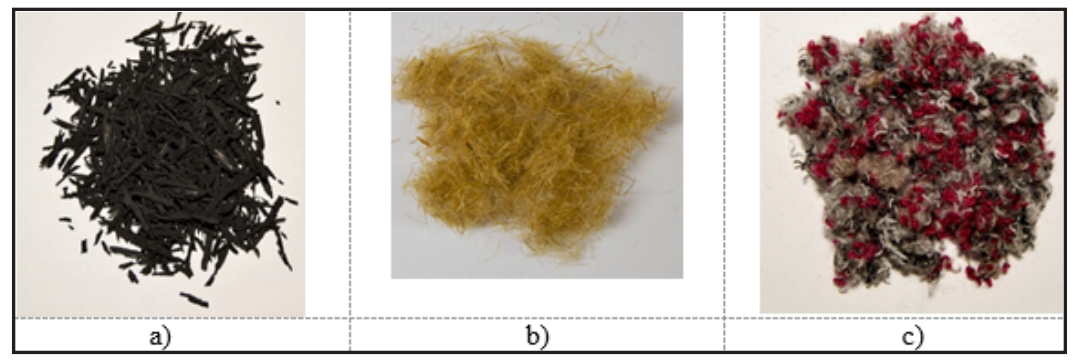

\begin{tabular}{|c|c|c|c|c|}
\hline \multirow{2}{*}{ Code } & \multicolumn{2}{|c|}{ Waste materials } & \multirow{2}{*}{$\begin{array}{c}\text { Rigid } \\
\text { polyurethane } \\
\text { foam (wt } \% \text { ) }\end{array}$} & \multirow{2}{*}{$\begin{array}{c}\text { Apparent } \\
\text { density } \\
\left(\mathrm{g} / \mathrm{cm}^{3}\right)\end{array}$} \\
\hline & Type & wt $\%$ & & \\
\hline R10RPF & \multirow{5}{*}{ Rubber crumbs } & 10 & 90 & 0.038 \\
\hline R15RPF & & 15 & 85 & 0.044 \\
\hline R20RPF & & 20 & 80 & 0.062 \\
\hline R40RPF & & 40 & 60 & 0.075 \\
\hline R50RPF & & 50 & 50 & 0.102 \\
\hline F10RPF & \multirow{2}{*}{ Flex fibre } & 10 & 90 & 0.034 \\
\hline F15RPF & & 15 & 85 & 0.039 \\
\hline T10RPF & \multirow{3}{*}{ Textile waste } & 10 & 90 & 0.036 \\
\hline T15RPF & & 15 & 85 & 0.053 \\
\hline T2ORPF & & 20 & 80 & 0.057 \\
\hline RPF & - & - & 100 & 0.04 \\
\hline
\end{tabular}

The flax fibres (fig. 1b)) used in this study are flax waste resulting from the melt process, with a density of $0.02 \mathrm{~g} /$ $\mathrm{cm}^{3}$.

Textile waste (fig. 1c) contains synthetic fibres from the production of knitted clothing, with a density of $0.03 \mathrm{~g} /$ $\mathrm{cm}^{3}$.

Polyol and isocyanate were mixed with recycled rubber crumbs; flax; textile waste at determined weight ratios. A mixer tool of up to $2000 \mathrm{rpm}$ was used to mix the composition in order to obtain a homogeneous composition.

At the beginning of the study different weight percentage ( $w t \%)$ of waste materials in polyurethane foam were established.

In this study, 11 panels samples were obtained, made of waste materials and rigid polyurethane foam as binder. The samples characteristics are shown in table 1 . The thickness was measured parallel along the foam rise direction. The samples had a thickness of $40 \mathrm{~mm}$.
Fig. 1 Waste materials: a) recycled rubber crumbs; b) flax fibres; c) textile waste

Table 1

SAMPLE PREPARATION
Thermal conductivity

Determination of thermal conductivity coefficient was performed according to the standard SR EN 12667/2002 by heat flow meter method, with the FOX 200 Heat Flow Meter device. The samples had a size of $15 \times 15 \times 4 \mathrm{~cm}$ and the temperature range was $0 \div 20^{\circ} \mathrm{C}$.

\section{Sound absorption coefficient measurement}

To determine the acoustic properties of the insulating composites used, the sound absorption coefficients were determined by the impedance tube method. The materials measurements were based on the two-microphone transfer-function method, according to ISO 10534-2 [25], which are for horizontally mounted orientation sensitive samples.

In this study a medium Brüel\&Kjaer Type 4206 A tube kit was used to measure various acoustic parameters for the frequency range of $100 \div 3200 \mathrm{~Hz}$. Medium impedance tube kit consisted of a $63.5 \mathrm{~mm}$ diameter tube and therefore tests were performed on circular samples with a diameter of $63.5 \mathrm{~mm}$ (fig. 2).

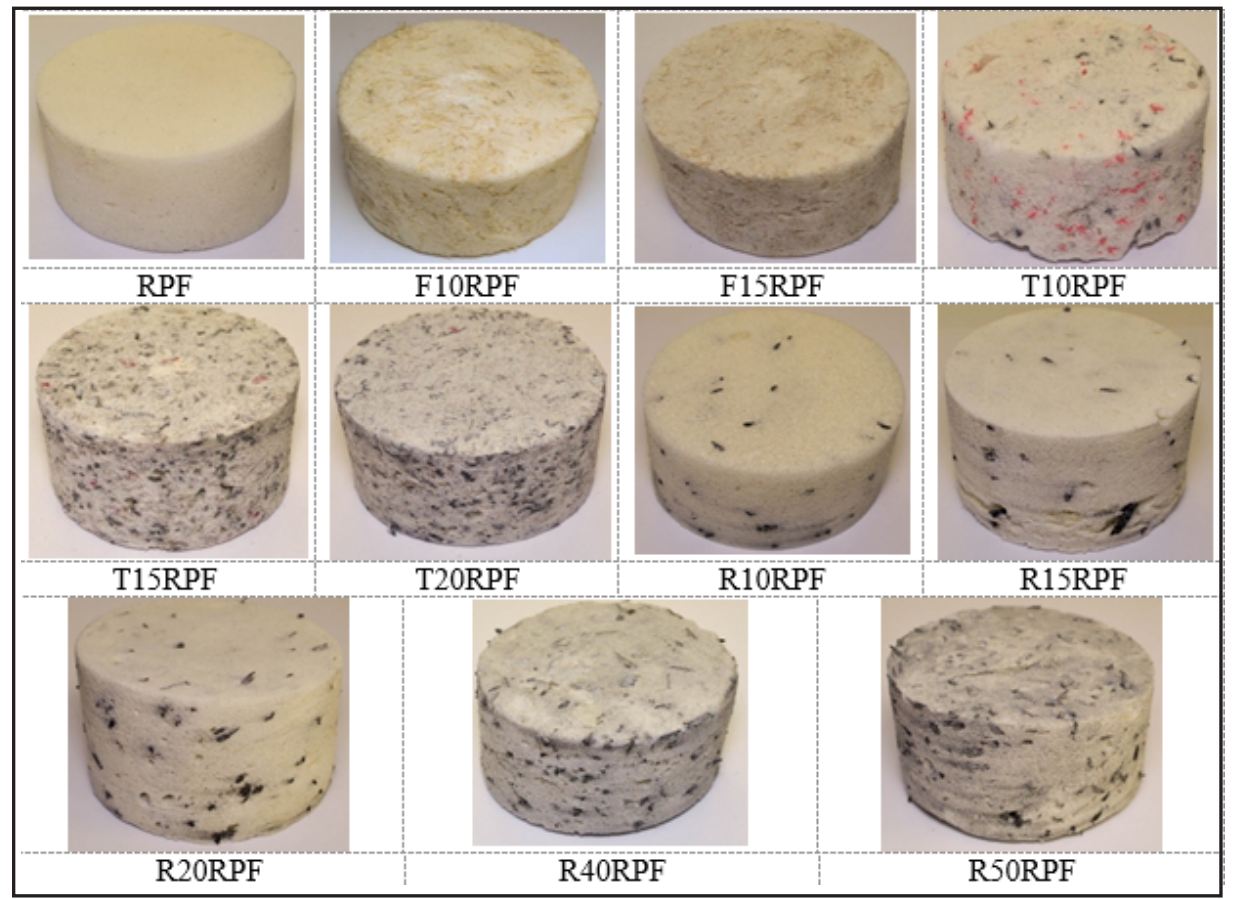

Fig. 2 Samples prepared for sound absorption coefficient measurement 


\section{Results and discussions}

Results for thermal conductivity tests

Insulation is one of the most effective methods intended for reducing energy consumption in both heating and cooling of buildings. Selecting the right materials and determining the optimum insulation thickness in building insulation application is an important issue [24].

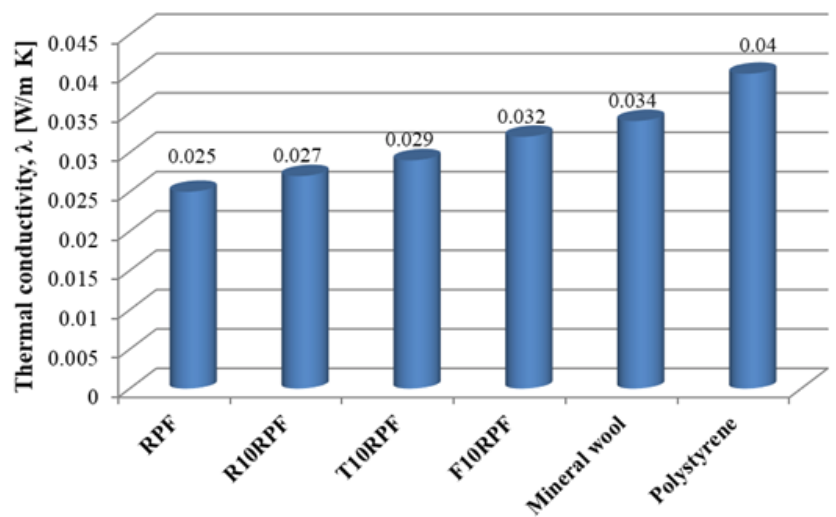

Fig. 3. Thermal conductivity values

Figure 3 shows thermal conductivity of the following sound absorbing materials: $100 \%$ rigid polyurethane foam (RPF); $10 \%$ flax fibre with $90 \%$ rigid polyurethane foam (F10RPF); $10 \%$ textile waste with $90 \%$ rigid polyurethane foam (T10RPF); $10 \%$ recycled rubber with $90 \%$ rigid polyurethane foam (R1ORPF); polystyrene and mineral wool. Analysed samples had $40 \mathrm{~mm}$ thickness.

According to the plot (fig. 3), it can be seen that the samples thermal conductivity is low er when compared to the existing materials on the market (polystyrene and mineral wool), which means they have the best thermal insulation properties. It can be seen that for the three materials with $90 \%$ rigid polyurethane foam: F1ORPF $(0.032$ $\mathrm{W} / \mathrm{m} \mathrm{K})$, T1ORPF $(0.029 \mathrm{~W} / \mathrm{m} \mathrm{K})$ and R10RPF $(0.027 \mathrm{~W} / \mathrm{m}$ $K)$ there is an improvement in thermal conductivity when compared to the rigid polyurethane foam, which is one of the most efficient thermal insulators. Obtained values show better thermal insulation properties when compared to the mineral wool $(0.034 \mathrm{~W} / \mathrm{m} \mathrm{K})$ and polystyrene $(0.04$ $\mathrm{W} / \mathrm{m} \mathrm{K}$ ).

It is important to highlight also that the innovative materials made for this study show higher thermal conductivity when compared to other innovative materials based on textile waste according to literature [24] .

Also it can be seen in figure 3 the influence on thermal conductivity of material used for preparing the composites. Thus, the recycled rubber crumbs mixed with polyurethane matrix influences the least the thermal insulation properties, while flax fibres show a slight decrease of thermal insulation when compared to the $100 \%$ rigid polyurethane foam. Recycled rubber has the highest density when compared to the other recycled materials used in this study. Also, because the mixes are based on mass percents, the rubber volume added to the mix is the lowest.

\section{Results of acoustic tests}

The raw materials used in the composite materials have a very important role in defining the sound absorbing properties because they define the internal structure of the composite materials.

Measurement data was processed and the sound absorption coefficient variation with frequency plots were drawn; based on a $1 / 3$ octave spectrum.
The effect of rigid polyurethane foam percentage on sound absorption coefficient

Figure 4 shows the influence on acoustic absorption coefficient of the binder percent used in composites. Materials used contain various percents of rigid polyurethane foam, as follows: $100 \%, 90 \%$ and $85 \%$; the rest being filled with flax fibre.

It can be seen that in the case of the rigid polyurethane foam and 15\% flax fibers (F15RPF), the acoustic absorption coefficient improves in the frequency range of $100 \mathrm{~Hz} \div$ $850 \mathrm{~Hz}, 1500 \mathrm{~Hz} \div 3200 \mathrm{~Hz}$, when compared to the $100 \%$ rigid polyurethane foam material. Also, the material with $80 \%$ polyurethane foam and $10 \%$ flax fibers (F1ORPF), show an improvement of the sound wave absorption in the frequency range of $1650 \mathrm{~Hz} \div 2350 \mathrm{~Hz}$, when compared to the F15RPF sample material.

As seen in figure 5 , showing the acoustic absorption coefficient variation with the percentage of binder mixed with textile waste, the acoustic absorption coefficient improves when compared to the other materials used, in the frequency range of $100 \mathrm{~Hz} \div 850 \mathrm{~Hz}$ in the case of $80 \%$ rigid polyurethane foam and $20 \%$ textile waste (T2ORPF).

Also, the T10RPF material shows much better sound wave absorption properties in the frequency range of 1100 $\mathrm{Hz} \div 2800 \mathrm{~Hz}$ when compared to the $100 \%$ rigid polyurethane foam sample.

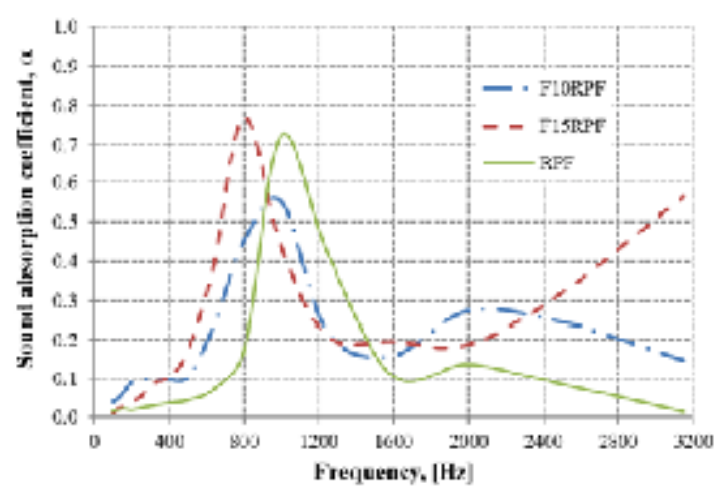

Fig. 4. Variation of the acoustic coefficient absorption with the percent of binder used in materials with flax fibers

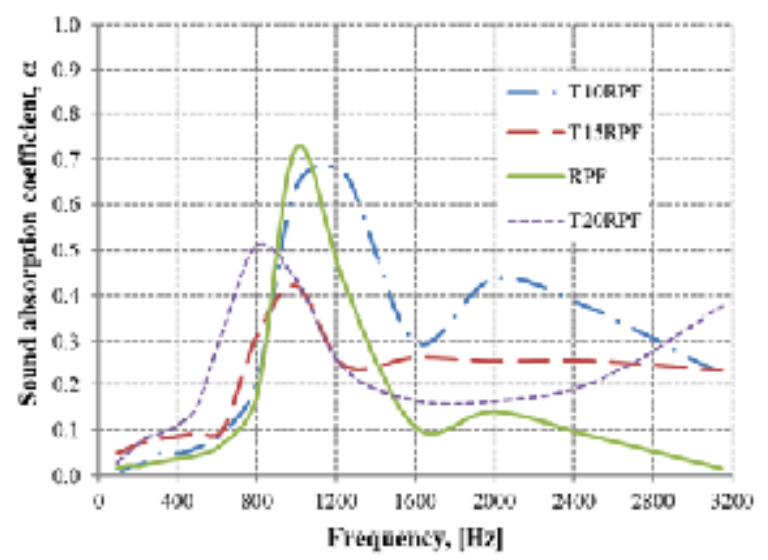

Fig. 5. Variation of acoustic coefficient absorption with the percent of binder mixed with textile waste

Figure 6 shows the acoustic absorption coefficient variation with the percent of rigid polyurethane foam mixed with recycled rubber crumbs. Analyzed materials contain a percent of $100 \%, 90 \%, 85 \%, 80 \%, 60 \%$ and $50 \%$ rigid polyurethane foam.

Material which contains $90 \%$ rigid polyurethane foam and $10 \%$ recycled rubber (R10RPF) show much better values of the acoustic absorption coefficient when 


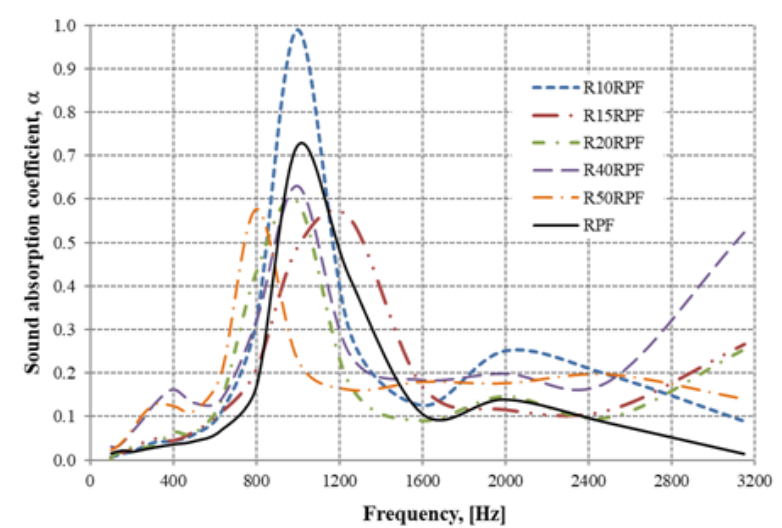

Fig. 6. Variation of acoustic absorption coefficient with the percent of binder used in materials that contains recycled rubber

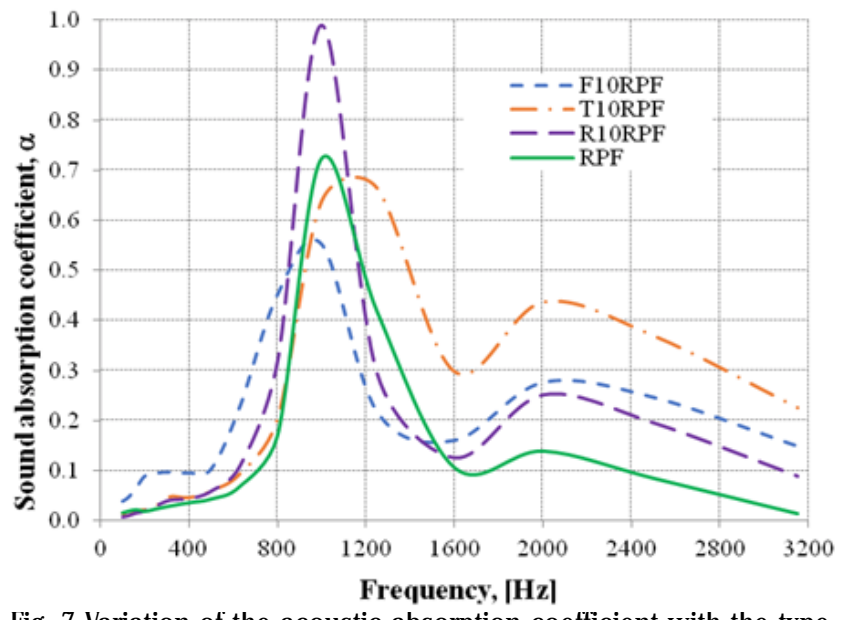

Fig. 7 Variation of the acoustic absorption coefficient with the type of waste used

compared to the other materials analyzed, in the frequency range of $800 \mathrm{~Hz} \div 1150 \mathrm{~Hz}$ and $1700 \mathrm{~Hz} \div 2400 \mathrm{~Hz}$.

In the frequency range of $1150 \mathrm{~Hz} \div 1600 \mathrm{~Hz}$, the R15RPF sample material shows the best acoustic absorption coefficient when compared to the other materials.

Also, material R40RPF shows better values of the acoustic absorption coefficient when compared to the other materials, in the frequency range of $2500 \mathrm{~Hz} \div 3200$ $\mathrm{Hz}$.

The effect of the type of waste materials on sound absorption coefficient

In Figure 7 can be seen that in the frequency range of $100 \mathrm{~Hz} \div 800 \mathrm{~Hz}$, the $90 \%$ rigid polyurethane foam mixed with $10 \%$ flax fibers (F1ORPF) shows the best value of the acoustic absorption coefficient.

The material which contains $90 \%$ rigid polyurethane foam mixed with $10 \%$ recycled rubber (R1ORPF) shows better sound wave absorption properties in the frequency range of $800 \mathrm{~Hz} \div 1100 \mathrm{~Hz}$.

Following the plot analysis we can conclude that the material with $90 \%$ rigid polyurethane foam mixed with $10 \%$ textile waste (T1ORPF) has an acoustic absorption coefficienthigher that the other materials, in the frequency range of $1100 \mathrm{~Hz} \div 3200 \mathrm{~Hz}$.

It can be concluded that by the use of $10 \%$ waste in the analyzed mixtures, the sound wave absorption properties improve in all frequency ranges studied, when compared to the $100 \%$ rigid polyurethane foam material (RPF).

\section{Conclusions}

Addition of recycled rubber crumbs, flax fibres or textile waste to polyurethane foam does not induce a significant change in the thermal conductivity of the composites.
Although the differences are not significant, the lowest thermal conductivity value was observed for the composite containing $10 \%$ recycled rubber crumbs. As an additional benefit, by increasing the waste materials content in the composite, the amount of polyurethane foam used is reduced, thus lessening the environmental impact and reducing the cost of the developed material.

Composite materials obtained by adding $10 \%$ waste materials to rigid polyurethane foam matrix have sound absorption properties much improved compared to the $100 \%$ rigid polyurethane foam.

The composite materials can be safely used for manufacturing panels with acoustic absorption properties for use in industry, road, rail or air transportation.

\section{References}

1.HUNG, T.-C., HUANG, J.-S., WANG, Y.-W., LIN, K.-Y., Constr. Build. Mater., 50, 2014, p. 328.

2.YAM, R.C.M., MAK, D.M.T, J. Clean. Prod., 67, 2014, p. 277.

3.ERIKSSON O., Renew. Energ., 61, 2014, p. 38.

4.GLISCINSKA, E., MICHALAK, M., KRUCIÑSKA, I., KAZIMIERCZAK, J., BLODA, A., CIECHAÑSKA, D., J ournal of Chemistry and Chemical Engineering, 7, 2013, p. 942.

5.KRUCINSKA, I., GLISCINSKA, E., MICHALAK, M., CIECHANSKA, D., KAZIMIERCZAK, J., BLODA, A., Text. Res. J., 85, nr. 6, 2015, p. 646. 6.AKAYDIN, M., YILMAZ, K., YILMAZ, N.D., Indian. J. Fibre. Text., 40, 2015, p. 301.

7.KOIZUMI, T., TSUJ IUCHI, N., ADACHI, A., The Development of Sound Absorbing Materials Using Natural Bamboo Fibers, High Performance, WIT Press, 2002.

8.GLE, P., GOURDON, E., ARNAUD, L., Appl. Acoust., 72, 2011, p. 249. 9.FATIMA, S., MOHANTY, A.R., Appl. Acoust., 72, 2011, p. 108. 10.THIL AGAVATHI, G., PRADEEP, E., KANNAIAN, T., SASIKALA, L., J. Ind. Text., 39, 2010, p. 267.

11.FOULADI, M., Appl. Acoust, 72, 2011, p. 35.

12.SHAN, C.W., IDRIS, M.I., GHAZALI, M.I., Int. J. Appl. Phy. Math., 2, nr. 2, 2012, p. 123.

13.CURTU, I., STANCIU, M.D., COSEREANU, C., VASILE, O., Mat Plast., 49, no.1,2012, p. 68.

14.J AYAMANI, E., HAMDAN, S., HENG, S.K., RAHMAN, M. R., Appl. Mech. Mater., 663, 2014, p. 464.

15.POPITA, G.E., ROSU, C., MANCIULA, D., CORBU, O., POPOVICl, A., NEMES, O., SANDU, A.V., PROOROCU, M., DAN, S.B., Mat. Plast., 53, no. 2, 2016, p. 308.

16.SABAU, E., BALC, N., BERE, P., NEMES, O., Studia Universitatis Babes-Bolyai Chemia, 57, nr. 4, 2012, p. 201.

17.PLATON, M.A., STEF, M., POPA, C., TIUC, A.E., NEMES, O., IOP Conference Series: Materials Science and Engineering, 374, nr.1, 2018.

18.EKICI, B., KENTLI, A., KUCUK, H., Arch. Acoust., 37, nr. 4, 2012, p. 515.

19.FORMELA, K., HEJ NA, A., ZEDLERA, L., PRZYBYSZA, M., RYLB, J., Ind. Crop. Prod., 108, 2017, p. 844.

20.NEMES, O., LACHAUD, F., PIQUET, R., SOPORAN, V.-F., TATARU, O., Studia Universitatis Babes-Bolyai Chemia, 53, nr. 3, 2008, p.25.

21.ZHOU, H., LI, B., HUANG, G.S., HE, J., J. Sound. Vib., 304, 2007, p. 400.

22.***Directive 2002/91/EC Energy Performance of Buildings, OJ L EU L 1/65, 2003.

23.PEREZ, G., RINCON, L., VILA, A., GONZALEZ, J.M., CABEZAA, L.F., Appl, Energy, 88, 2011, p. 4854.

24.RICCIARDI, P., BELLONI, E., COTANA, F., Appl. Energy, 134, 2014, p. 150.

25.***Standard SR EN ISO 10534-2, Determination of sound absorption coefficient and acoustic impedance with the interferometer. Part 2. Transfer function method, 2002.

$\overline{\text { Manuscript received:21.05.2018 }}$ 